\title{
Erratum to: New Autism Diagnostic Interview-Revised Algorithms for Toddlers and Young Preschoolers from 12 to 47 Months of Age
}

\author{
So Hyun Kim • Catherine Lord
}

Published online: 1 November 2011

(C) Springer Science+Business Media, LLC 2011

\section{Erratum to: J Autism Dev Disord}

DOI 10.1007/s10803-011-1213-1

In Fig. 1 as published in this article, the graph in the middle is the same as the first one (just first two bars in the first graph)—which is an error. The correct version of Fig. 1 is given.
$12-20 / \mathrm{NV} 21-47$

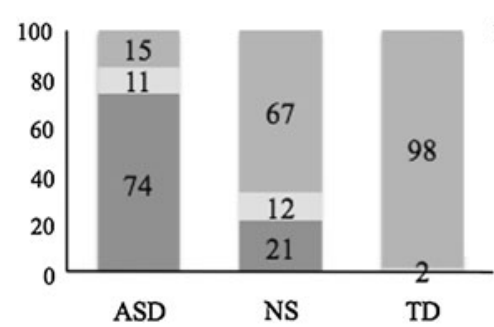

ASD

NS

TD

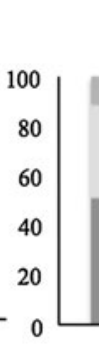

ASD
SW21-47

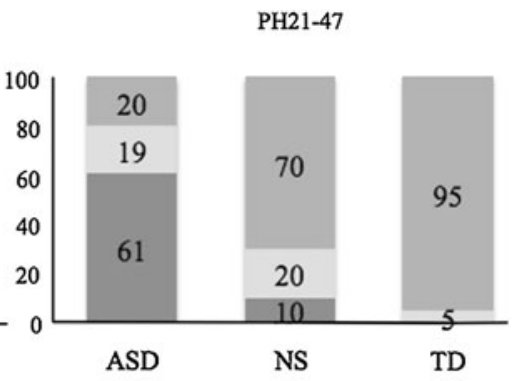

= Little-to-No Concern Mild-to-Moderate Concern

= Moderate-to-Severe Concern

Little-to-No Concern $=$ scores 0 - 10 Mild-to-Moderate Concern $=$ scores 11-13 Moderate-to-Severe Concern $=$ scores $14+$

Little-to-No Concern $=$ scores $0-7$ Mild-to-Moderate Concern $=$ scores 8-13 Moderate-to-Severe Concern $=$ scores $14+$
Little-to-No Concern $=$ scores $0-12$ Mild-to-Moderate Concern $=$ scores $13-16$ Moderate-to-Severe Concern $=$ scores $17+$

12-20 Children from 12 to 20 months of age, NV21-47 Nonverbal children from 21 to 47 months of age, SW21-47 Children with single words from 21-47 months of age; PH21-47 Children with phrase speech from 21-47 months of age. ASD Autism Spectrum Disorder, NS Nonspectrum disorder, TD Typical Development

Fig. 1 Percent of participants falling into ranges of concern by diagnostic group

The online version of the original article can be found under doi:10.1007/s10803-011-1213-1.

S. H. Kim $(\bowtie) \cdot$ C. Lord

University of Michigan Autism and Communication Disorders

Center (UMACC), 1111 Catherine St, Ann Arbor,

MI 48109-2054, USA

e-mail:sohkim@umich.edu 